\title{
Principios éticos de la reanimación cardiopulmonar y cerebral
}

\section{Ethical principles of cardiopulmonary and cerebral resuscitation}

Prof. Dra. Idoris Cordero-Escobar, ${ }^{*}$ Prof. Dra. Caridad de Dios Soler-Morejón ${ }^{\ddagger}$

\section{INTRODUCCIÓN}

Segutebris egún Naninni(1), el hombre es una persona y como tal es sujeto de derechos. Por tanto, debe tratarse con dignidad en todas sus dimensiones. Por lo que todos los hombres tienen derecho a una vida digna y también a una muerte digna.

La Deontología Médica es el conjunto de principios y reglas éticas que deben guiar la conducta profesional del médico. Su conocimiento debe ser básico para todos los profesionales que ejercen la medicina ${ }^{(2)}$.

El Código Deontológico es el documento que recoge un conjunto amplio de criterios apoyados en la deontología, que incluye normas y principios que formulan y a su vez resumen quienes realizan correctamente una actividad profesional( ${ }^{(2)}$.

Se define la ética como la disciplina que estudia los comportamientos humanos desde el punto de vista moral, del acercamiento al «bien» o al «mal», mientras que la bioética es la parte de la ética relacionada con las ciencias de la vida ${ }^{(3-5)}$.

Según Encyclopedia of Bioethics, se define la bioética como el estudio sistemático de la conducta humana en el ámbito de las ciencias de la vida y del cuidado de la salud, examinada a la luz de los valores y de los principios morales ${ }^{(6)}$.

Desde 1971, se conceptualiza como un neologismo introducido por el oncólogo Van Rensselaer Potter. Se utilizó por primera vez en una monografía titulada «Bioethics: bridge to the future». Se ha convertido en uno de los temas de obligada referencia en la medicina y la investigación actual. Constituye una nueva disciplina que ha adquirido a lo largo de los últimos treinta años un importante cuerpo doctrinal, convirtiéndose en una de las ramas de estudio más desarrolladas de la ética ${ }^{(7,8)}$.

El consenso internacional sobre paro cardíaco, conocido como «Estilo Utstein», define éste como el cese de la actividad mecánica cardíaca, confirmado por la ausencia de conciencia, pulso detectable y respiración (o respiración agónica entrecortada). La muerte súbita cardíaca es la que ocurre de modo inesperado, dentro de la primera hora del comienzo de los síntomas, en pacientes cuya situación previa no hacía previsible un desenlace fatal. Muerte súbita y paro cardiorrespiratorio (PCR) suelen usarse como sinónimos. Ambos son conceptos de límites arbitrariamente establecidos en torno a un mismo fenómeno. El concepto de muerte súbita tiene un enfoque fundamentalmente epidemiológico, y el de PCR es de orientación clínica ${ }^{(9-12)}$.

El cambio a la definición se vincula con la organización de la atención al PCR y su objetivo es ofrecer una pauta al personal que atiende a la víctima para la puesta en marcha de una secuencia asistencial conocida como «cadena de supervivencia»(13-15).

Aunque las causas del paro respiratorio y cardíaco son diversas, desde el punto de vista asistencial se tiende a considerar como una entidad única denominada PCR. La interrupción de una de las dos funciones vitales lleva rápida e indefectiblemente a la detención de la otra, por lo que su conducta se aborda de forma conjunta. El conjunto de medidas aplicadas para
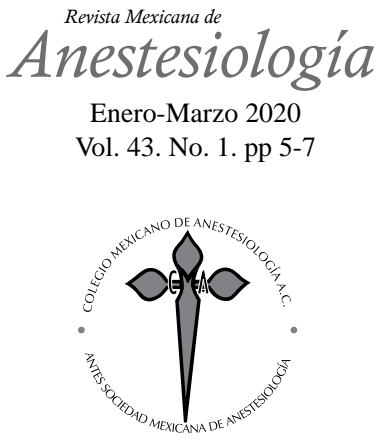

\footnotetext{
* Especialista en Anestesiología y Reanimación. Doctora en Ciencias. Profesora e Investigadora Titular. ORCID: 0000-0001-9877-3113.

‡ Especialista en Medicina Intensiva y emergencias. Doctora en Ciencias Médicas, Profesora e Investigadora Titular. ORCID: 0000-0003-2695-3291.
}

Hospital Clínico Quirúrgico «Hermanos Ameijeiras». La Habana, Cuba.

Solicitud de sobretiros: Prof. Dra. Idoris Cordero-Escobar E-mail: csoler@infomed.sld.cu ice@infomed.sld.cu

Recibido para publicación: 04-02-2019 Aceptado para publicación: 06-05-2019 
tratar el PCR ha sido denominado reanimación. La reanimación cardiopulmonar (RCP) se define como el conjunto de maniobras encaminadas a revertir el PCR, por lo cual se sustituye su funcionamiento inicialmente, para intentar restaurar después la respiración y circulación espontáneas con el fin de evitar la muerte por lesión irreversible de órganos vitales, especialmente del cerebro. Se distinguen dos niveles de RCP: básica y avanzada ${ }^{(16)}$.

Estos principios han dado lugar a un relanzamiento de la ética médica, enriquecida con nuevas formulaciones y argumentaciones, en los que la competencia profesional y los datos obtenidos de la evidencia científica se convierten en requisitos básicos para la toma de decisiones morales. Precisamente, esta confrontación, armonización de datos científicos y dilemas éticos distingue la nueva Bioética de la Clásica Deontología Médica enunciada por Hipócrates ya en el siglo V a.C.; surge, por tanto, esta nueva área de conocimiento y de discusión que parte de cómo una necesidad de logros, de acuerdos a nivel de la comunidad científica internacional pueden asegurar el respeto a la vida humana y a la dignidad personal en el ámbito de la investigación científica y el trabajo biomédico ${ }^{(17,18)}$.

La presencia creciente de recursos o demandas legales en los que personas provenientes del ámbito del Derecho (sin vinculación alguna con la experiencia de la práctica clínica o quirúrgica) deben decidir la licitud del obrar médico, ponen de manifiesto la necesidad de la existencia de un cuerpo de doctrina establecido en el que se definen los criterios éticos que pueden justificar (o no) la toma de decisiones cuestionables en los cuidados de la salud ${ }^{(19)}$.

Por estas razones, los residentes de la especialidad, deben tener estos principios incorporados en su aprendizaje, de tal manera que una vez graduados tengan suficientes conocimientos y habilidades sobre el tema.

El objetivo de este artículo, es actualizar los principios éticos de la Reanimación Cardiopulmonar y Cerebral, en el ámbito de la Anestesiología y Reanimación.

\section{DESARROLLO}

Los principios éticos relacionados con la reanimación resultan complejos, pues se producen en diferentes entornos: hospitalarios o extrahospitalarios. Deben estar presentes entre distintos tipos de reanimadores (legos o profesionales), pueden estar relacionados con el inicio o la culminación del apoyo vital básico o avanzado y pueden estar influenciadas por factores individuales, de la cultura local e internacional, legal, de la tradición, religiosa, social y económica. Estas situaciones de emergencia vital hacen más difícil la toma de decisiones ${ }^{(13-17)}$. Se deben guiar por los conocimientos científicos, las preferencias de las personas, por la normativa local y los requisitos legales siempre basados en los principios básicos de la ética.

La Reanimación Cardiopulmonar y Cerebral (RCP-C), se practica de acuerdo a las recomendaciones basadas en los consensos internacionales actualizados periódicamente por el
ILCOR (International Liaison Committee on Resuscitation) según las mejores evidencias científicas disponibles y en Europa por el European Resuscitation Council quien adecua las recomendaciones sobre RCP del ILCOR a las condiciones y peculiaridades del continente ${ }^{(17-20)}$.

Las últimas guías incluyen un capítulo sobre cuestiones éticas a considerar en la RCP-C, el cual emana preferentemente de la cultura anglosajona. En España, el Plan Nacional de RCP realiza una labor de educación, difusión y puesta al día de los consensos europeos.

Las normas ILCOR sugieren que las víctimas de un PCR deben ser asistidas con técnicas, procedimientos y terapéuticas sustentados en los principios básicos de la ética, en la medicina basada en la evidencia y en la experiencia.

Las decisiones en RCP-C son tomadas por los rescatistas en cuestión de segundos por lo que a veces pueden surgir conflictos.

Forman parte de la bioética, la beneficencia, la no maleficencia, la autonomía y la justicia, relacionadas con la integridad, la eficiencia, la confidencialidad y la fidelidad, la autonomía relacionada directamente con el paciente, la beneficencia con la relación médico paciente, la no maleficencia con el médico y la justicia con la sociedad.

Los principios generales de beneficencia, no maleficencia, autonomía y justicia parecen ser aceptados en distintas culturas, pero la prioridad de estos principios puede variar entre ellas.

Principio de beneficencia. Es el principio ético primero de las actuaciones médicas y responde al fin primario de la medicina, que es el promover el bien para el enfermo y la sociedad. En él se han fundamentado los códigos médicos, desde el Juramento Hipocrático ${ }^{(3)}$.

En el ámbito médico, este principio obliga al profesional de la salud a poner el máximo empeño en atender al paciente y hacer cuanto pueda para mejorar su salud, de la forma que considere más adecuada ${ }^{(5)}$.

Lo principal, debe ser obtener el bien para el paciente asistido y tratar de devolver la vida con un mínimo de calidad. Implica que el personal de salud tiene la obligación de proveer beneficio en el mejor interés de cada paciente y hacer un balance entre riesgo y beneficio ${ }^{(5)}$. Frecuentemente, esto puede involucrar los intentos de reanimación; pero puede ser también del mantenimiento de la RCP o su suspensión ${ }^{(3)}$.

Principio de no maleficencia. Lleva implícito no hacer mal y aún más, no extender el daño. La reanimación no se debe intentar en casos donde obviamente es inútil. Está contraindicada cuando va contra los deseos expresos del paciente competente. Se trata de evitar cualquier acción que pueda tener efecto negativo sobre el bien deseado. Los procedimientos contraindicados no pueden ni deben realizarse ni aun con el consentimiento del paciente. Los procedimientos inútiles o fútiles se consideran en este grupo.

Principio de autonomía. Este principio se basa en la convicción que el ser humano debe ser libre de todo control exterior y ser respetado en sus decisiones vitales básicas ${ }^{(8)}$. 
Se refiere al respeto debido a los derechos fundamentales del hombre, incluido el de la autodeterminación. Es un principio profundamente enraizado en el conjunto de la cultura occidental, aunque ha tardado en tener repercusiones en el ámbito médico. Significa el reconocimiento que el ser humano, también el enfermo, es un sujeto y no un objeto. En el caso específico de la autonomía el paciente tiene derecho, si es competente y se ha informado debidamente, a rechazar o aceptar la RCP aunque en su negativa vaya su propia vida ${ }^{(6)}$.

Significa que los pacientes pueden tomar las decisiones informadas en su propio nombre, en lugar de sujetarse únicamente a las decisiones de los profesionales de la salud. Este principio es universal en la práctica médica, e incluye el PCR y la RCP-C ${ }^{(9)}$.

Requiere que el paciente competente sea adecuadamente informado, sin presión externa de nadie y que sus preferencias sean consistentes.

Todos los adultos se consideran capaces de tomar decisiones, excepto los que están legalmente declarados incapaces ${ }^{(11-15)}$.

En caso que el sujeto no pueda tomar decisiones, se deben considerar los deseos de éste cuando estaba consciente, preferentemente expresados por escrito (orden de no resucitar) o la decisión subrogada de un familiar priorizado por el grado de parentesco ${ }^{(19)}$.
El principio de autonomía debe prevalecer sobre el resto, sin olvidar que la libertad es una posibilidad para decidir y que para decidir hay que entender.

Principio de justicia. La aplicación del principio de justicia surge del de igualdad entre todos los seres humanos. Implica el concepto y la obligación de distribuir los limitados recursos de salud equitativamente dentro de la sociedad ${ }^{(8,9)}$.

Conflictos éticos. Surge ante el conflicto de la autonomía, la beneficencia y la no maleficencia, las cuales en ocasiones entran en contradicciones.

La RCP se debe aplicar si está indicada, omitirse si no lo está o no fue previamente aceptada por el paciente y suspenderse si es inefectiva.

Si la RCP se previera fútil, se registrará una orden de no intentar resucitación, que deberá ser conocida por los profesionales sanitarios que atienden al enfermo. Es aceptable limitar el apoyo vital a los supervivientes con encefalopatía hipóxica, si se descarta la posibilidad que evolucione a la muerte encefálica ${ }^{(12)}$.

Se concluye que se hace necesario enseñar los principios éticos de la reanimación cardiopulmonar y cerebral, en el ámbito de los residentes de Anestesiología y Reanimación, así como a los paramédicos para que los integren desde etapas tempranas de su formación e incluirlos en los programas de enseñanza en los que no se encuentren incorporados.

\section{REFERENCIAS}

1. Nannini D. Ética de la resucitación cardio-pulmonar (RCP). Federación Argentina de Cardiología. Segundo Congreso Virtual de Cardiología. 2001. [En Línea]. (Consultado 2018). Disponible en: URL: www.fac.org. ar/scvc/llave/PDF/nannin.

2. Monsieurs KG, Nolan JP, Bossaert LL, Greif R, Maconochie IK, Nikolaou NI, et al. ERC Guidelines for resuscitation 2015. Resuscitation 2015. [Online] (Accessed June 2018). Available in: URL https://ercguidelines. elsevierresource.com/european-resuscitation-council-guidelinesresuscitation-2015-section-1-executive-summary.

3. Vera CO. Conducta ética en el paro cardiorrespiratorio 2016. [En línea] (Consultada Junio 2018). Scielo 2016. Disponible en: URL http://www.scielo. org.bo/scielo.php?script=sci_arttext\&pid=S1726-89582016000100011.

4. Maconochie I. When should ADULT CPR be delivered to children? Resuscitation. 2018;122:A4-A5.

5. Mancini ME, Diekema DS, Hoadley TA, Kadlec KD, Leveille MH, McGowan JE, et al. Part 3: Ethical Issues: 2015 American Heart Association Guidelines Update for Cardiopulmonary Resuscitation and Emergency Cardiovascular Care. Circulation. 2015;132:S383-96.

6. Encyclopedia of bioethic. 3er ed. Editor Stephen G. ISBN 0-02-865774-8. 2004.

7. Soreide E, Morrison L, Hillman K. The formula for survival in resuscitation. Resuscitation. 2013;84:148.

8. Monzón L, Saralegui I, Molina R, Abizanda R, Cruz Martín M, Cabré L. Ética de las decisiones en resucitación cardiopulmonar. Med Intensiva. 2010;34: [En línea] (Consultado 15 agosto 2018). Disponible en: URL: http://scielo. isciii.es/scielo.php?script=sci_arttext\&pid=S0210-56912010000800006.

9. Gómez J. Ética en medicina crítica. Cap. 5. Muerte clínica y reanimación cardiopulmonar. Madrid: Triacastela, 2002. pp. 119-31.

10. Perales N, Abizanda R, Rubio M. Ética y resucitación cardiopulmonar. En: Perales N, López J, Ruano M. Manual de soporte vital avanzado. Barcelona: Elsevier-Doyma; 2007. pp. 261-273.

11. Bradley SM, Liu W, Chan PS, Girotra S, Goldberger ZD, Valle JA, et al. Duration of resuscitation efforts for in-hospital cardiac arrest by predicted outcomes: insights from get with the guidelines resuscitation. Resuscitation. 2017;113:128-134.

12. Brooks SC, Schmicker RH, Cheskes S, Christenson J, Craig A, Daya M. Variability in the initiation of resuscitation attempts by emergency medical services personnel during out-of-hospital cardiac arrest. Resuscitation. 2017;117:102-108.

13. McKay A, Walker ST, Brett SJ, Vincent Ch, Sevdalis N. Team performance in resuscitation. Comparison and critique of two recently developed scoring tools. Resuscitation. 2012;83(12):1478-1483.

14. Siao FY, Chiu CC, Chiu CW, Chen YC, Chen YL, Hsieh YK, et al. Managing cardiac arrest with refractory ventricular fibrillation in the emergency department: conventional cardiopulmonary resuscitation versus extracorporeal cardiopulmonary resuscitation. Resuscitation. 2015;92:7076.

15. Peigh G, Cavarocchi N, Hirose H. Saving life and brain with extracorporeal cardiopulmonary resuscitation: A single-center analysis of in-hospital cardiac arrests. J Thorac Cardiovasc Surg 2015;150:1344-1349.

16. Riggs KR, Becker LB, Sugarman J. Ethics in the use of extracorporeal cardiopulmonary resuscitation in adults. Resuscitation. 2015;91:73-75.

17. Li J, Li Ch, Yuan W, Wu J, Li Z, Zhao Y. Mild hypothermia alleviates brain oedema and blood-brain barrier disruption by attenuating tight junction and adherens junction breakdown in a swine model of cardiopulmonary resuscitation. PLoS One. 2017;12:e0174596.

18. Geri G, Mongardon N, Daviaud F, Empana JP, Dumas F, Cariou A. Neurological consequences of cardiac arrest: where do we stand? Ann Fr Anesth Reanim. 2014;33:98-101.

19. Díaz GE, Cedillo FJM, Reza OM, Amezcua MA. La otra forma de morir; la Ley de Voluntad Anticipada. Acta Médica Grupo Ángeles. 2013;11:4145.

20. Bossaert LL, Perkins GD, Askitopoulou H, Raffay VI, Greif R, et al. Guidelines for resuscitation 2015. Section 11. The ethics of resuscitation and end-of-life decisions. Resuscitation. 2015;95:302-311. 